\title{
Performance Evaluation Based on DEA / PCA Model of Logistics Industry in Shandong Province
}

\author{
Lu Liu \\ School of Logistics Engineering Academy, Wuhan University of Technology, Wuhan430063, China. \\ 1140380341@qq.com
}

Keywords: DEA; PCA; Logistics industry; Performance evaluation

\begin{abstract}
In order to promote the development of the logistics industry in Shandong Province, the paper utilizes DEA / PCA comprehensive evaluation model to evaluate the logistics performances of 17 cities in Shandong Province by selecting appropriate inputs and outputs indicators. The paper selects the fixed-asset investment, personnel and highway mileage three elements as the input indicators, total logistics amounts,added value of logistics industry and tonnage mileage three elements as output indicators.Firstly, the two methods were used to evaluate the logistics performance of Shandong Province respectively.Then,the results of these two methods will be compared and synthesized to the two-dimensional quadrant screen for intuitive analysis and evaluation. So the development level of logistics industry of every city in Shandong Province can be gained. In addition, the paper also gives suggestions for the improvement of logistics industry in Shandong Province, which contribute to provide theory and decision support for the development of logistics industry in Shandong Province.
\end{abstract}

\section{Introduction}

With the development of economics and the improvement level of opening up in China, the status of the logistics industry in China's economy continues to strengthen. As one of the top ten revitalizing industry, the logistics industry is playing a significant role in improving China's GNP and stabilizing the market economy.In addition, it also contributes to regulating supply and demand of the market , increasing social spending and expanding the market reach.Shandong Province is located in eastern coastal region of China and the Bohai Economic Zone.The advantageous location promotes the rapid development of the logistics industry. In 2013, the total amount of social logistics in Shandong Province has reached 17.15 trillion yuan, with year-on-year growth of $14.1 \%$. And the logistics industry has realized added value 402.48 billion yuan, accounting for $7.4 \%$ of GDP, which demonstrates the rapid development of the logistics industry in Shandong Province powerfully. In this case, the performance evaluation of the logistics industry in Shandong Province is very essential. Reasonable performance evaluation can provide certain support for the development of the logistics industry in Shandong Province.And it can also provide a reference for other areas about the evaluation of logistics industry.

\section{DEA / PCA evaluation model}

Data envelopment analysis (DEA), which is proposed by A.Charnes, WWCooper and E.Rhodes, is to put each of the plurality of decision making units with multiple inputs and outputs indicators integrate into one input-output ratio indicator for relative effectiveness evaluation, while providing recommendations for improvement of the non-effective decision making units. Principal component analysis (PCA) is a multivariate statistical analysis method which has been widely used as a multi-index comprehensive evaluation and sorting to reflect a comprehensive analysis of the biggest differences between the evaluation objects. The paper utilizes a combination of these two methods.Firstly,the two methods were used to evaluate the logistics performance of Shandong 
Province respectively.Then, the results of these two methods will be compared and synthesized to the two-dimensional quadrant screen for intuitive analysis and evaluation[1].

\section{Empirical Analysis}

In this paper, 17 cities in Shandong Province are the decision making units.Selecting the fixed-asset investment, personnel and highway mileage three elements as the input indicators, total logistics amounts, added value of logistics industry and tonnage mileage three elements as output indicators[2]. According to the data in $<$ Logistics Yearbook of China $>$ and $<$ Statistical Yearbook of Shandong Province >in 2014, you can get the table of logistics inputs and outputs of 17 cities in Shandong Province, as is shown in Table 1.

Table 1 The Logistics Inputs and Outputs of 17 Cities in Shandong Province

\begin{tabular}{|l|l|l|l|l|l|l|}
\hline & \multicolumn{3}{|c|}{ Input Factors $\mathrm{x}_{\mathrm{i}}$} & \multicolumn{3}{c|}{ Output Factors $\mathrm{y}_{\mathrm{i}}$} \\
\hline Cities & $\begin{array}{l}\text { Fixed-asset } \\
\text { Investment[billi } \\
\text { on yuan] } \mathrm{x}_{1}\end{array}$ & $\begin{array}{l}\text { Personn } \\
\text { el[perso } \\
\mathrm{n} \mathrm{x}_{2}\end{array}$ & $\begin{array}{l}\text { highway } \\
\text { mileage[k } \\
\mathrm{m} \mathrm{x}_{3}\end{array}$ & $\begin{array}{l}\text { total } \\
\text { logistics } \\
\text { amounts[billi } \\
\text { on yuan] } \mathrm{y}_{1}\end{array}$ & $\begin{array}{l}\text { added value } \\
\text { of logistics } \\
\text { industry[bill } \\
\text { ion yuan] } \mathrm{y}_{2}\end{array}$ & $\begin{array}{l}\text { tonnage } \\
\text { mileage[ } \\
\text { Millions } \\
\text { ton-km] } \mathrm{y}_{3}\end{array}$ \\
\hline Jinan & 263.83 & 49000 & 12697 & 1522.53 & 37.15 & 32072 \\
\hline Qingdao & 502.79 & 88000 & 16270 & 2707.26 & 70.86 & 92344 \\
\hline Zibo & 207.85 & 13000 & 10924 & 1482.52 & 30.41 & 89327 \\
\hline Zaozhuang & 123.82 & 11000 & 8007 & 460.89 & 12.77 & 31177 \\
\hline Dongying & 233.21 & 5000 & 8609 & 1293.61 & 12.98 & 17892 \\
\hline Yantai & 353.82 & 48000 & 17024 & 1839.32 & 27.90 & 79644 \\
\hline Weifang & 342.99 & 30000 & 25225 & 1563.93 & 33.12 & 89250 \\
\hline Jining & 218.83 & 20000 & 18198 & 827.88 & 23.86 & 69161 \\
\hline Taian & 198.18 & 17000 & 14329 & 906.45 & 16.74 & 17214 \\
\hline Weihai & 192.37 & 15000 & 7060 & 842.15 & 15.17 & 29972 \\
\hline Rizhao & 106.90 & 24000 & 8153 & 527.35 & 14.55 & 41039 \\
\hline Laiwu & 47.26 & 6000 & 4161 & 245.74 & 7.32 & 5867 \\
\hline Linyi & 243.16 & 32000 & 25577 & 2125.60 & 42.04 & 102885 \\
\hline Dezhou & 168.66 & 18000 & 21587 & 935.25 & 17.32 & 38724 \\
\hline Liaocheng & 151.11 & 23000 & 17402 & 1077.97 & 17.86 & 42399 \\
\hline Binzhou & 151.72 & 10000 & 15858 & 841.59 & 15.34 & 35605 \\
\hline Heze & 81.08 & 16000 & 21704 & 712.25 & 15.68 & 72610 \\
\hline
\end{tabular}

The DEA Method of logistics industry in Shandong Province. The DEA model $\left(C^{2} R\right.$ model $)$ is shown below.

$\operatorname{Min} \theta$

$\left\{\begin{array}{l}\sum_{j=1}^{\mathrm{n}} \mathrm{x}_{j} \lambda_{j}+S^{-}=\theta x_{0} \\ \sum_{j=1}^{\mathrm{n}} \mathrm{y}_{j} \lambda_{j}-S^{+}=y_{0} \\ \lambda_{\mathrm{j}} \geq 0, \mathrm{j}=1,2 \ldots \mathrm{n} \\ S^{+} \geq 0, S^{-} \geq 0\end{array}\right.$

Plugging the data in Table 1 into Eq. 1 and using Lingo software to solve,the corresponding $\theta$, $\lambda_{\mathrm{j}}, S^{-}, S^{+}$can be gotten.If $\theta=1$, and there is $S^{-}=S^{+}=0$, then the DEA performance of $\mathrm{j}$-th unit 
is effective in its optimal solution; If $0<\theta<1$, then the DEA performance of $\mathrm{j}$-th unit is not effective. And in most cases, the value of the $\theta$ is smaller, indicating its effectiveness worse. In addition, for non-DEA efficient units, they can be further noted the gap and the direction of improvement by computing the value of $\sum_{j=1}^{n} \lambda_{\mathrm{j}}$. If $\sum_{j=1}^{n} \lambda_{\mathrm{j}}>1$, it is indicated that the economics of scale is diminishing.On the contrary, when $\sum_{j=1}^{n} \lambda_{\mathrm{j}}<1$, the economics of scale is increasing[3].The results are as shown in Table 2.

The PCA Method of logistics industry in Shandong Province.Dealing with the data in Table 1 , the ratio of the index can be defined as below[4].

$$
\begin{aligned}
& d_{i r}^{j}=y_{r j} / x_{i j} \\
& d_{k}^{j}=d_{i r}^{j}
\end{aligned}
$$

Using SPSS software for principal component analysis to deal with the ratio.The mathematical model of taking first $m$ principal components is

$$
\begin{aligned}
& F_{\mathrm{n}}=a_{1 n} x_{1}+a_{2 n} x_{2}+\cdots+a_{q n} x_{q} \\
& \mathrm{a}_{i n}=p_{i n} / \sqrt{\lambda_{n}}
\end{aligned}
$$

And the comprehensive evaluation model of the first $m$ principal components is

$$
F=\sum_{j=1}^{m} \frac{\lambda_{j}}{\sum_{j=1}^{m} \lambda_{j}} F_{j}
$$

As is seen from the results of SPSS software, the contribution rates for the first three principal components are $31.952 \%, 29.883 \%, 23.102 \%$, and the cumulative contribution rate is $84.937 \%$.As $84.937 \%>80 \%$, the three principal components can represent the original data basically[5].

Combined with the results of SPSS, the comprehensive evaluation model on principal component analysis can be obtained by using Eq.4, Eq.5, Eq.6,as is shown in Eq.7.

$$
F=0.3758 \bullet F_{1}+0.3514 \bullet F_{2}+0.2717 \bullet F_{3}
$$

According to the Eq.7, the PCA scores and rank of 17 cities in Shandong Province can be obtained separately, as shown in Table 2.

Table 2 Logistics Performance Evaluation of 17 Cities in Shandong Province

\begin{tabular}{|l|l|l|l|l|l|l|}
\hline NUM & DMU & $\begin{array}{l}\text { DEA score } \\
\text { values } \theta\end{array}$ & $\begin{array}{l}\text { PCA score } \\
\text { values F } \quad \begin{array}{l}\text { Scores } \\
\text { Sorting of } \\
\text { DEA }\end{array}\end{array}$ & $\begin{array}{l}\text { Scores } \\
\text { Sorting of } \\
\text { PCA }\end{array}$ & $\begin{array}{l}\text { economy of } \\
\text { scale }\end{array}$ \\
\hline 1 & Jinan & 0.952 & 0.006 & 6 & 7 & increasing \\
\hline 2 & Qingdao & 1.000 & 1.298 & 1 & 2 & constant \\
\hline 3 & Zibo & 1.000 & 2.655 & 1 & 1 & constant \\
\hline 4 & Zaozhuang & 0.675 & -0.388 & 15 & 10 & increasing \\
\hline 5 & Dongying & 1.000 & 0.940 & 1 & 3 & constant \\
\hline 6 & Yantai & 0.770 & -0.186 & 11 & 8 & diminishing \\
\hline 7 & Weifang & 0.619 & -0.421 & 16 & 11 & increasing \\
\hline 8 & Jining & 0.694 & -0.444 & 13 & 13 & increasing \\
\hline 9 & Taian & 0.596 & -1.189 & 17 & 17 & increasing \\
\hline 10 & Weihai & 0.794 & 0.096 & 10 & 6 & increasing \\
\hline 11 & Rizhao & 0.870 & -0.228 & 8 & 9 & increasing \\
\hline 12 & Laiwu & 0.940 & -0.725 & 7 & 15 & increasing \\
\hline 13 & Linyi & 1.000 & 0.616 & 1 & 4 & constant \\
\hline 14 & Dezhou & 0.679 & -1.038 & 14 & 16 & increasing \\
\hline
\end{tabular}




\begin{tabular}{|l|l|l|l|l|l|l|}
\hline 15 & Liaocheng & 0.816 & -0.663 & 9 & 14 & increasing \\
\hline 16 & Binzhou & 0.769 & -0.429 & 12 & 12 & increasing \\
\hline 17 & Heze & 1.000 & 0.101 & 1 & 5 & constant \\
\hline & Mean value & 0.834 & 0 & & & \\
\hline
\end{tabular}

From the DEA score values in the Table 2,it can be seen that the score values of Qingdao, Zibo, Dongying, Linyi and Heze five cities are 1,showing that they are DEA effective[6]. While the DEA score values of remaining 12 cities are less than 1, so they are not DEA effective.By calculating $\sum_{j=1}^{n} \lambda_{\mathrm{j}}$, the 12 cities which are not DEA effective are all $\sum_{j=1}^{n} \lambda_{\mathrm{j}}<1$ except Yantai, indicating that only Yantai should decrease the scale of logistics properly to improve its logistics performance, while the remaining 11 non-DEA effective cities should increase their logistics scale[7].It can be seen that the logistics scale of most of the city in Shandong Province are needed to be improved.

At the same time, it can also be seen that the mean PCA score values of 17 cities is 0 . And Zibo, Qingdao, Dongying, Linyi, Heze, Weihai, Jinan seven cities are better than average, Yantai, Rizhao, Zaozhuang, Weifang, Binzhou, Jining, Liaocheng, Laiwu, Dezhou, Taian 10 cities are below the level of average

DEA / PCA comprehensive Evaluation of the logistics industry in Shandong Province. Sorting the scores of DEA and PCA respectively and using sign test method of non-parametric statistical method to the sorted results of the two methods for no evident difference test[8] . Specific method is:using $C_{\mathrm{i}}(\mathrm{i}=1,2, \ldots, 17)$ represent difference between of the $\mathrm{i}$-th DEA evaluation ordering and the PCA evaluation ordering, such as $C_{1}=-1$. The number of $C_{\mathrm{i}}>0$ is a, and the number of $C_{\mathrm{i}}<0$ is b.Checking the sign test table,you can get the critical value $S_{\alpha}(\mathrm{m})$ while $\mathrm{m}=\mathrm{a}+\mathrm{b}$, and $\alpha$ is the significant level. If $\min (\mathrm{a}, \mathrm{b})>S_{\alpha}(\mathrm{m})$, there is no significant difference in the sorting results of the two methods.So it can be used for theoretical analysis. On the contrary, it is showed that the two methods are significantly different and can not be used for theoretical analysis.

By calculating the data,you can get $\mathrm{a}=4, \mathrm{~b}=9$. So $\mathrm{m}=13$, min $(\mathrm{a}, \mathrm{b})=4$. By looking up the sign test table, you can get $S_{0.05}(13)=2$. Because $4>2$, it is accorded with $\min (\mathrm{a}, \mathrm{b})>S_{\alpha}(\mathrm{m})$. Therefore, the sorting results of the two methods are no significant difference.And then,the theoretical analysis is proved feasible.

The evaluation value of two methods are distributed in two-dimensional coordinates on the screen,as is shown in Fig. 1 below, where the horizontal axis is the DEA evaluation score whose boundary is 0.7 , and the vertical axis is the PCA valuation score whose boundary is 0.And the two axis divide the plane into $\mathrm{A}, \mathrm{B}, \mathrm{C}, \mathrm{D}$ four regions.



Figure. 1 DEA / PCA Evaluation of Two-dimensional Coordinates 
As is shown above,Zibo, Qingdao, Dongying, Linyi, Heze, Jinan, Weihai seven cities are in A zone, indicating that the logistics industry inputs and outputs of the seven cities are relatively high.So their logistics performances are excellent,especially Zibo, Qingdao, Dongying, Linyi, Heze five cities which are DEA effective[9].While Yantai, Binzhou, Liaocheng, Rizhao and Laiwu five cities which are in the B zone due to the low scores of the overall indicators of large differences between the ratio of inputs and outputs, their development of the logistics industry are in the middle level.The two results of evaluation of the cities in D region,including Tai'an, Weifang, Zaozhuang, Jining,dezhou five cities, are both lower, indicating that their logistics development are needed to be improved .

\section{Summary}

The paper gives a comprehensive evaluation about the logistics industry performance in Shandong Province by using DEA and PCA two evaluation methods. From the result,you can learn that many cities' logistics industry are in the state of scale increasing. So a conclusion can be drawn that the logistics scale in Shandong Province is needed to be improved in most places.And There is a great space for development of logistics industry in Shandong Province.To improve the developing level of logistics in Shandong Province,there are some suggestions.

Firstly,the cities in D region should focus on the development of the logistics industry.Expanding the scale of logistics and bringing advanced logistics technology may help a lot.Meanwhile, cities in A region should maintain the good momentum of the logistics industry to develop and promote the development of the logistics industry around the cities as much as possible. Especially the cities located in the coastal areas,including Qingdao, Dongying, Weihai three cities, should take full advantage of the superior geographic location to develop port logistics.Then, Yantai, Binzhou, Rizhao, Weifang four cities are also in the coastal areas ,but their logistics development have to be further improved in the future. Focusing on the development of coastal logistics by improving logistics scale and expanding the amount of logistics will contribute to the performance of logistics. At the same time, cities which are in the non-coastal areas should mainly develop inland logistics by greatly improve freight volume of highways and railways.Last but not least, all cities should devote more efforts to support the development of third-party logistics enterprises and cultivate outstanding logistics personnel. Developing logistics information technology industry and enhancing the establishment of logistics infrastructure effectively are also significant for the development of logistics[10].Only in this way, the logistics industry in Shandong Province can develop better and better!

\section{References}

[1] Gang Du , Junpeng Guo, Jianguo Zhang etc.DEA / PCA analysis model of industrial economic evaluation, J.Journal of Tianjin University (Social Sciences), 2000,2 (4).

[2] Youxin Zeng, Likui Du. The logistics industry performance evaluation based on DEA model in Jiangsu Province, J. Chinese Market, 2012 (41).

[3]Siyun Chen,Jun Peng.The logistics performance evaluation of ports based on PCA and DEA model, J.Logistics Engineering and Management,2012,34 (2).

[4]Xiaojing Feng.The performance evaluation of logistics parks based on PCA and DEA model, D.Xi'an:Chang'an University,2012.

[5] Haifeng Wang.New and high technology industries economic performance evaluation based on DEA / PCA model, J. Decision Making, 2012 (7). 
[6]Xiaoyang Zhang.The efficiency research of regional logistics industry in China, J.Hebei Enterprises,2012(3).

[7] Bin Yang, Xuewei Bai, Lisha Bai.Carbon emission efficiency evaluation of logistics industry based on PCA and DEA model in Jiangsu Province, J. Jiangsu University of Science and Technology (Natural Science), 2014,28 (2).

[8]Bin Shuai.The economics of logistics industry, M.4 th,Beijing:Science Press,2006.

[9]Jie Gao.The international competitiveness evaluation based on DEA/PCA model of Chinese provincial tourism, J. The Border Economy and Culture,2014(2).

[10] Li Tian.The logistics industry performance evaluation based on DEA model in Henan Province, J. Techniques and Methods, 2015,34 (1). 